Nucleic acids revised

The Biochemistry of the Nucleic Acids. Eighth edition. By J. N. Davidson. Pp.xii + 420. (Chapman and Hall: London, October 1976.) Hardcovers £8.50; papercovers $£ 4.50$.

THE late Professor Davidson wrote seven invaluable editions of this book over twenty years of exciting discovery in nucleic acid biochemistry. The eighth edition by four of his former students and colleagues at Glasgow (R. L. P. Adams, R. H. Burdon, A. M. Campbell and R. M. S. Smellie) packs a mine of information into a volume that can still be put into a coat pocket. It emphasises the enzymology of nucleic acids with a sound foundation of their structural analysis and physicochemical properties. Some chaptersespecially that on the replication of DNA-form really advanced reviews. An excellent feature is the skill and authority with which important properties of prokaryotic and eukaryotic polymerases are compared. The book is copiously documented with many important references, has few errors or ambiguities in proportion to the wealth of its content, and is priced very reasonably, especially in the paperback edition.

Although this new edition will follow its predecessors in being an important source book in nucleic acid biochemistry, the role of the book may perhaps be changing. Nucleic acids were, for many years, treated poorly in even the best general biochemistry texts. Today, such texts may contain excellent sections on nucleic acids and Davidson's book is no longer needed to introduce students to the field. It still has no equal in providing the necessary background for those who are contemplating or beginning a research project in nucleic acid biochemistry.

Yet it is a pity that the eighth edition has lost the freshness of the first and does not bubble with the excitement and imagination that is still typical of much nucleic acid research. Some sections-for example, those on DNA sequencing or protein synthesis, are quite disjointed, presumably as a result of too much scissors and paste. There is no glimmer of the rich prospects opened up by the ability to recombine DNA in vitro and to clone the artificial recombinants. Several good electron micrographs of nucleic acids are shown, but the techniques are not outlined, and the value of electron microscopy is not emphasised enough. The relationships between nucleus and cytoplasm as may, for example, be illustrated in histone biosynthesis are not explained. The relevance of 6-Oalkylation of guanine to chemical mutagenesis is not mentioned. Indeed, mutagenic screening tests to identify potential environmental carcinogens are not discussed.

In view of its reasonable price, one can forgive most of the cramped blackand-white diagrams. But some are so bad they cannot be excused. In particular, the numbered purine and pyrimidine ring structures are so tiny that they can hardly be read. Certain diagrams of replicating Escherichia coli DNA do not show two-directional replication and one shows linear chromosomes. A bacterial cell is drawn to imply that all ribosomes occur free in the cytoplasm instead of being generally attached to messenger RNA which can still be attached to the DNA.

Despite the usefulness of this new edition and the extensive revision that it has undergone, I think that more revision is still needed as the pace of discovery has been fast. Dubious or outdated items should be pruned, certain diagrams revised and the authors encouraged to bring out crucial features of selected experiments and to re-introduce a forward look.

Kenneth Burton

Kenneth Burton is Professor of Biochemistry at the University of Newcastle upon Tyne, UK.

\section{Perspective on penicillin}

Penicillin in Perspective. By David Wilson. Pp. xi + 298. (Faber and Faber: London, October, 1976.) £4.95.

IT is now nearly half a century since Fleming's famous observation of the action of penicillin on a contaminated plate. This was followed, over a decade later, by the demonstration of its chemotherapeutic possibilities by a small group of workers at Oxford led by the late Lord Florey, which revolutionised the treatment of infection and triggered the explosive development of the multi-million pound antibiotics industry.

Because of its glamour and the ease with which the early work on penicillin can be grasped by the layman, several popular books on it or on antibiotics in general have appeared. Can yet another be justified? On reading the most aptly named Penicillin in Perspective, initial scepticism on this point is quickly replaced by respect for the thoroughness with which the author has researched his material and the freshness of his approach; even those already familiar with the story will find more than a little that is new to them. The interweaving of the main theme with relevant background is skillfully done, and there are fascinating sidelights on personalities and circumstances. The part played by luck repeatedly recurs, and among a number of interesting speculations is whether, in these days of stringent official control of new drugs (perhaps partly in response to ill-informed public clamour) penicillin would ever have reached clinical medicine. There are a good number of quotations, some quite long, from original papers, from correspondence and from other books, which add interest and authority, and complement the author's compact but clear style.

It is good to find credit given to some of the little-known workers in the field, such as F. Ridley and (the late) Stuart Craddock, two medical students at St Mary's Hospital who, working under great difficulties, prepared a protein-free penicillin which could surely have been used for protective experiments in mice. Precisely why these crucial experiments were not attempted will never be known, but a fairly convincing explanation is offered in terms of the general scientific outlook at the time, the particular climate of opinion in Wright's laboratory, and Fleming's own character.

Few significant errors have been noticed: the barium salt of penicillin was not crystallised in 1941 (p183); penicillins I, II, III, and IV in the British nomenclature correspond to $\mathrm{F}, \mathrm{G}, \mathrm{X}$ and $\mathrm{K}$ respectively in that of the US (p16). A more serious inaccuracy is the claim (by the author) that the Oxford workers "found out how to manufacture penicillin on a commercial scale" (p141). It is true that they carried out culture of the fungus on what, for a research laboratory, was a very large scale, but the yield of penicillin was so painfully low (at most 2 units $\mathrm{ml}^{-1}$ ) that the total production to the middle of 1941 and the completion of the trials on the first six parenterally treated patients at the Radcliffe Infirmary, was probably less than 5 megaunits. With modern highyielding strains of the fungus in deep culture this amount could be obtained from less than half a pint of culture fluid!

This is indeed a worthwhile book and presents a sober, critical and well informed view of penicillin in perspective.

N. G. Heatley

N. G. Heatley was formerly Senior Research Officer, and is now Lecturer, at the Sir William Dunn School of Pathology, University of Oxford, UK. 